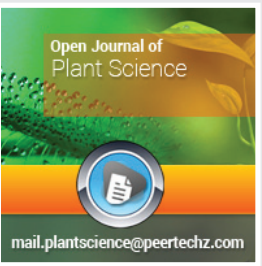

Life Sciences Group

\title{
Open Journal of Plant Science
}

\section{Mohiuddin $\mathrm{AK}^{*}$}

Assistant Professor, Faculty of Pharmacy, World University of Bangladesh

Received: 31 December, 2018

Accepted: 25 January, 2019

Published: 28 January, 2019

*Corresponding author: Mohiuddin AK, Assistant Professor, Faculty of Pharmacy, World University of Bangladesh, 151/8, Green Road, Dhanmondi, Dhaka 1205, Bangladesh, E-mail: trymohi@gmail.com

Keywords: Medicinal Plants; Medical Pluralism; Folk Healers; Spiritual Healing; Herbal Drugs

https://www.peertechz.com

Check for updates
Research Article

\section{A Brief Review of Traditional plants as} Sources of Pharmacological interests

\section{Abstract}

The knowledge base of pharmacy medicine is changing. Even five decades ago rural people used to visit kobiraj doctors for traditional medication mostly obtained from the roots and leaves of the remote plants (As seen in old dramas and movies). During 70's to 80', a modern allopathy system taken over most of it and plant medicines were completely became obsolete. However, the Bangladeshi traditional medicine is a unique conglomerate of different ethnomedical influences. Due to the geographic location and sociocultural characteristics of the country, it involves traditionally rooted elements influenced by local indigenous people and close-by Indian Ayurveda and Unani medicine. Given its inexpensive, easily accessible and well-established health services, the use of traditional medicine is an integral part of public health services in Bangladesh with its providers being deeply embedded within the local community. Recent data suggest that the utilization of traditional medicine health services in Bangladesh is widespread and plays a crucial role in providing health care for poor people, people in rural areas and for tribal people

Purpose of the study: An illustrated review of traditional Bangladeshi plants, their nature and their pharmacological use

Findings: A careful use of these plants can bring dramatic changes in the history of medicine, on the contrary abuse/misuse is just waste of money and also creates potential health hazards. The emerging use of plant derived medicines should have a proper quality control and system control of sales, distribution and use through strict vigilance.

Materials and Methods: A comprehensive literature review, consulting books, technical newsletters, newspapers, journals, and many other sources are done with this review. Health professionals like qualified doctors, chemists, company professionals have given their useful suggestions. A few folk healers' shops are also visited to see the real situation includes their sales policy, misleading claims without valid references. Pharma company representatives are also interviewed who are selling herb medicines as white-collar business. Few students of mine helped me by their feedback from previous experiences in visiting rural areas and use of folk medicine there. The article comprises both plant medicine and plants used for pleasure by general people.

\section{Abbreviations}

HDS: Herbs and Dietary Supplements; WAPIC: Western Australian Poisons Information Centre

\section{Introduction}

The concept of ethnopharmacology was first defined in 60 's which describes an approach to the discovery of single biologically active molecules that has been used ever since the first compounds were isolated from plant material. It should also be noted that the discovery of new drugs might derive from a wider use of plants than for strictly medical purposes alone. Thus, materials used as poisons, in pest control, in agriculture, as cosmetics, in fermentation processes and for religious purposes might also yield active substances that can be exploited as leads for drug development. However, article simply describes traditional plants of Bangladesh and their use because of the greater interest of general people, surprisingly, around $80 \%$ of the population of developing countries (according to WHO) now partially or fully dependent upon herbal drugs for primary healthcare. It should be remembered that Since the ingredients used are herbal, not only the ingredients often have added benefits that overall improve your health but there are chances of side effects.

\section{Traditional medicines: Contribution to modern medicine}

Ayurveda: With the term "Ayurveda" (AYUR means life, VEDA means Knowledge) translating to the 'science of life,' 
this traditional medical system is based on the belief that the human mind and body are deeply interconnected $[1,2]$. It reveals disease has been considered for fold (Body, mind, external factors and natural intrinsic causes). Being one of the oldest medical systems in the world, Ayurveda has its roots from the Vedic culture of India. The motto is simple- if you want to be healthy, your mind and bodily systems must be in balance and at harmony with each other [3,4]. Ayurvedic doctors prescribe a combination of medicines that often include essential oils, diet supplements and breathing exercises based on your DOSHA's. They are ultimate irreducible basic metabolic elements of living beings, determines the process of growth and decay. The TRIDOSHIC system was the fundamental concept of Ayurveda. They are classified into VATA (Air, causes emaciation, tremors, distention, constipation etc.), PITTA (Bile, which governs digestion, hunger, courage etc.) and Kapha (Phlegm, that holds together, gives lubrication, stability, causes nausea, cough and lethargy when becomes excess) [5]. The 'Samhitas,' or encyclopedia of medicine, were written during the post Vedic era, and include 'Charka Samhita' (900 BC), 'Sushruta Samhita' (600 BC) and Ashtanga Hridaya' (1000 CE). Utilization of plants was mentioned in Rigveda and Ayurveda (Veda, 3 types, there was also a Juju Veda). Charka Samhita was the first recorded treatise on Ayurveda (8 sections divided into 150 chapters, describing 341 medicinal plants. Another treatise of Ayurveda was Shushruta Samhita with special emphasis on surgery, although describing 395 medicinal plants, 57 drugs from animal origin and 64 minerals and metals as drugs $[6,7]$.

Unani: Contribution of Unani medical system to modern pharmacy is beyond description. In between $7^{\text {th }}$ to $8^{\text {th }}$ centuries, Arabs conquered a greater part of ancient civilized world, extending empire from Spain to India. During the reign of Caliph Harun-Al-Rashid (786-814 A.D), some Indian physicians were invited to Baghdad. Manaka, one of those physicians translated some book of Sanskrit to Arabic. Juhanna Ibn Masawaih translated Greek manuscripts to Arabic and wrote a medical book, 1st London Pharmacopoeia was largely based on his formulae. The Arabs greatly improved pharmaceutical products and made them more elegant and palatable. Their pharmacy and Materia Medica were followed for a long time. Arab pharmacists mixed rose water and perfumes with medicines. They invented tinctures, confections, syrups, pomade, plasters and ointments $[7,8]$.

Homeopathy: According to Homeopathy system until the potency governing the on the body of a human being is powerful and controls the functions of all organs. A disease produced in the body and brain will affect the other body organs, truly reveals modern day doctors saying, if your heart is weak, it will affect your kidneys someday. Or the ultimate untreated rheumatoid arthritis affects heart in a long run. However, there are three essential processes involved in preparation of remedies; serial dilution, succession and trituration (methods by which mechanical energy is delivered to our preparations in order to imprint the pharmacological message of the original drug upon the molecules of the diluent). Homeopathy's roots emerge from the findings, teachings and writings of Dr. Samuel Hahnemann (1755-1843). It was when Hahnemann began working on a project to translate William Cullen's Materia Medica into German that he began his quest for a better way of providing healthcare using the principles of "Similars." While working on this project, he became fascinated with a species of South American tree-bark (cinchona) which was being used to treat malaria-induced fever. Hahnemann ingested the bark and discovered that it caused symptoms similar to malaria. He continued his research into "cures" and the idea of "similar suffering," and began compiling his findings. Similia similibus curentur, the Latin phrase meaning "let likes be cured by likes," is the primary principle of homeopathy [9]. Today, nearly all French pharmacies sell homeopathic remedies and medicines; and homeopathy has a particularly strong following in Russia, India, Switzerland, Mexico, Germany, Netherlands, Italy, England, and South America. Homeopathy is also rising again in the United States. This resurgence has been documented by the National Center for Homeopathy in Virginia, which stated that Americans spent 230 million dollars on homeopathic remedies in 1996. It has also been said that sales are rising rapidly at about $12-15 \%$ each year.

Siddha System of Medicine: An ancient system of medicine, uses minerals and metals, mainly but some products of vegetable and/or animal origin also used. The Siddha system is based on a combination of ancient medicinal practices and spiritual disciplines as well as alchemy and mysticism. Hence medicine of the human is produced from PONCHOBUTA (PONCHOBOTI DAWAKHANA concept, mostly called in Bangladesh) theory (Gold, Lead, Copper, Iron and Zinc), where Gold and lead imparts maintenance of the body; Iron and Zinc generates electricity, employed in medicines that are administered for life extension. Copper used for heat preservation and other metals for body detoxification. Traditionally, it is taught that the siddhas laid the foundation for this system of medication. Siddhas were spiritual adepts who possessed the ASHTA siddhis, or the eight supernatural powers. Siddha medicine has been used for the management of chronic diseases and degenerative conditions, such as rheumatoid arthritis, autoimmune conditions, collagen disorders, and conditions of the central nervous system. Its effectiveness in those situations has varied $[7,10]$.

It is important to know that drugs are collected from various parts (Tables 1-6) of these plants for example: Barks (Cinnamon, Cinchona, Asoka); Roots (Podophyllum, Rauwolfia); Rhizomes (Ginger, Turmeric, Dioscorea); Leaves (Senna, Tulsi, Vasaka, Digitalis); Flowers (Saffron, Datura, Rose, Arnica); Fruits (Amla, Bael, Bahera, Almond, Cardamom); Seeds (Ispaghula, Linseed, Nux-vomica); Herbs (Chirata, Kalmegh, Pudina) [11,12].

\section{Traditional plants in treating major/minor ailments}

Through the centuries, sick people have been helped over and over again by remedies that did not arise out of the formal doctrines and procedures of the medical profession. The use of plants (Tables 2-5) to treat sickness is probably as old as mankind; formal medicine and medical degrees are, of course, much more recent. Yet if medicine is broadly defined as the attempt to treat and cure human illness, then the human beings who first grew and collected plants they thought useful, 
Table 1: Frequently Used Traditional Drugs in Different Ailments [7,14].

Disorders

Cough \& Cold

Urinary disorders

Arthritis and

Rheumatoid

disorders

sleep disorders

Cardiac

Others
Insomnia or other

\section{Plants used}

Leaves of Angelica, Garlic, Tulsi, Eucalyptus sp. dried stigma of Saffron, Ginger

Ispaghula husk, Senna leaves, honey (constipation), bark of Cascara, Cardamom, Cinnamon, Chirata (stomachic)

Kalmegh, Picrorhiza, Jar-amla (Cholagogue disorders); Arjuna, Punarnava (Diuretic ailments)

Rasna (Rheumatism), Gugul resin (anti-arthritic)

Ashwagandha, Belladonna, Datura, Cannabis, Hyoscyamus, Wild Cherry bark (Mild sedative)

Sarpagandha (hypotensive), Strophanthus (Cardiotonic)

Chenopodium oil (Anthelmintic) Vasaka (Anti-asthmatic), Turmeric, Punarnava, Ashwagandha (Anti-inflammatory)

Table 2: Frequently Used Traditional Plants with Specified Pharmacological Action [11].

\begin{tabular}{|c|c|}
\hline Pharmacological Action & Plant/Plant Part Used \\
\hline Anti-amoebic & Ipecuc root, Kurchi bark \\
\hline Anti-Asthmatic & Ephedra, Vasaka, Tylophora \\
\hline Anti-spasmodic & Belladonna, Datura, Hyoscyamus \\
\hline Analgesic & Opium, Cannabis \\
\hline Carminative & Cinnamon bark, Cardamom seed, Nutmeg fruit, Clove, \\
\hline Purgative & Caffron \\
\hline Bitter Tonic & Nux-vomica, Gentian, Picorhiza, Chirata, Kalmegh \\
\hline Cardiotonic & Digitalis, Squill, Strophanthus \\
\hline Tranquilizers & Rauwolfia Roots \\
\hline Expectorant & Benzoin, Tolu Balsam, Vasaka \\
\hline CNS action & Ergot, Belladonna, Stramonium, Ephedra, Physostigma \\
\hline
\end{tabular}

herbalists, and the first people to try to heal by the use of herbs, also called herbalists or herb doctors, must surely rank as pioneers of modern medicine [13].

Many Western medicines are based on traditional knowledge from Europe and the Mediterranean region. This is why interest is rapidly increasing in Indian and Chinese medicine, both of which represent a very long tradition of apparently safe use. However, these healthcare systems are different from Western medicine, so novel methods are required to verify the efficacy and safety of the therapies [15].

In the case of China, Western medicine was introduced in the sixteenth century, but it did not undergo any development until the nineteenth century. Before that, traditional medicine was the dominant form of medical care and still now plays an important role in China, and it is constantly being developed.

In the early development of modern medicine, biologically active compounds from higher plants have played a vital role in providing medicines to combat pain and diseases. For example, in the British Pharmacopoeia of 1932 , over $70 \%$ of organic monographs were on plant-derived products. However, with the advent of synthetic medicinal and subsequently of antibiotics, the role of plant derived therapeutic agents significantly declined in the economically developed nations [17]. Even in developed countries a variety of natural products enjoy their well-deserved recognition in the therapeutic arsenal. However, their actual and precise method of production is more or less an extremely individualized aspect.

\section{Commonly practiced home remedies with traditional medicines}

Bangladesh and a significant part of South Asia possess a vibrant and thriving medical pluralism. Traditional medicine continues to be a valuable source of remedies (Table 6) that have been used by millions of people around the world to secure their health. The various diseases treated included gastrointestinal disorders, jaundice, leucorrhea, tooth and gum disorders, helminthiasis, allergy, respiratory tract disorders, skin diseases, anemia, pain, and diabetes [19].

\section{Cosmetic uses of traditional medicine}

It is claimed that herbal cosmetics are natural and free from all the harmful synthetic chemicals which otherwise may prove to be toxic to the skin. Instead of traditional synthetic products different plant parts and plant extracts are used (Table 7) in these products, e.g. aloe Vera gel and coconut oil. There are a rising number of consumers who demand more natural products with traceable and more natural ingredients, free from harmful chemicals and with an emphasis on the properties of botanicals.

\section{Traditional medicines as potential antidotes}

Thousand claims of traditional medicines for anti-venom or antidotes (Table 8). Both spiritual healing (rituals) and plant medicines are practiced to detoxify and manage poisons of plant and animal origin. Folk medicines must be documented, validated and their practice be encouraged for the benefit of rural mass. Food-medicines overlap exhibited in many cultures can be an interesting area of investigation.

\section{Alternative medicine dispensing by the folk medicine practitioners}

Medical pluralism has led to an intrinsic feature of its medical system in historical and contemporary contexts. Folk medicines are widely practiced for primary healthcare, underlying factors such as economy, education, religion, culture, and environment. The KAVIRAJI treatment is also known as BONOJO CHIKTSYA (treatment by wild forest herbs) or VESHOJO CHIKITSYA (herbal treatment). They primarily use different Barks, Roots, Rhizomes, Leaves, Flowers, Fruits, Seeds, Herbs or other common items available in and around their homestead, collected from remote hills/forests or grown through cultivation. In some cases, they also perform rituals based on faiths, and recite holy verses (mantras). Three factors which legitimize the role of the folk healers include: their own beliefs, the beliefs of the community and the success of their actions. Nearly $40 \%$ of rural community members have superstitions/misbeliefs or strong beliefs on herb and approximately $15 \%$ treats simple ailments with herbs. They mostly use different plant extracts for different diseases. Some 
Table 3: Individual Plants/Plant Parts in Medicinal Use [7,16].

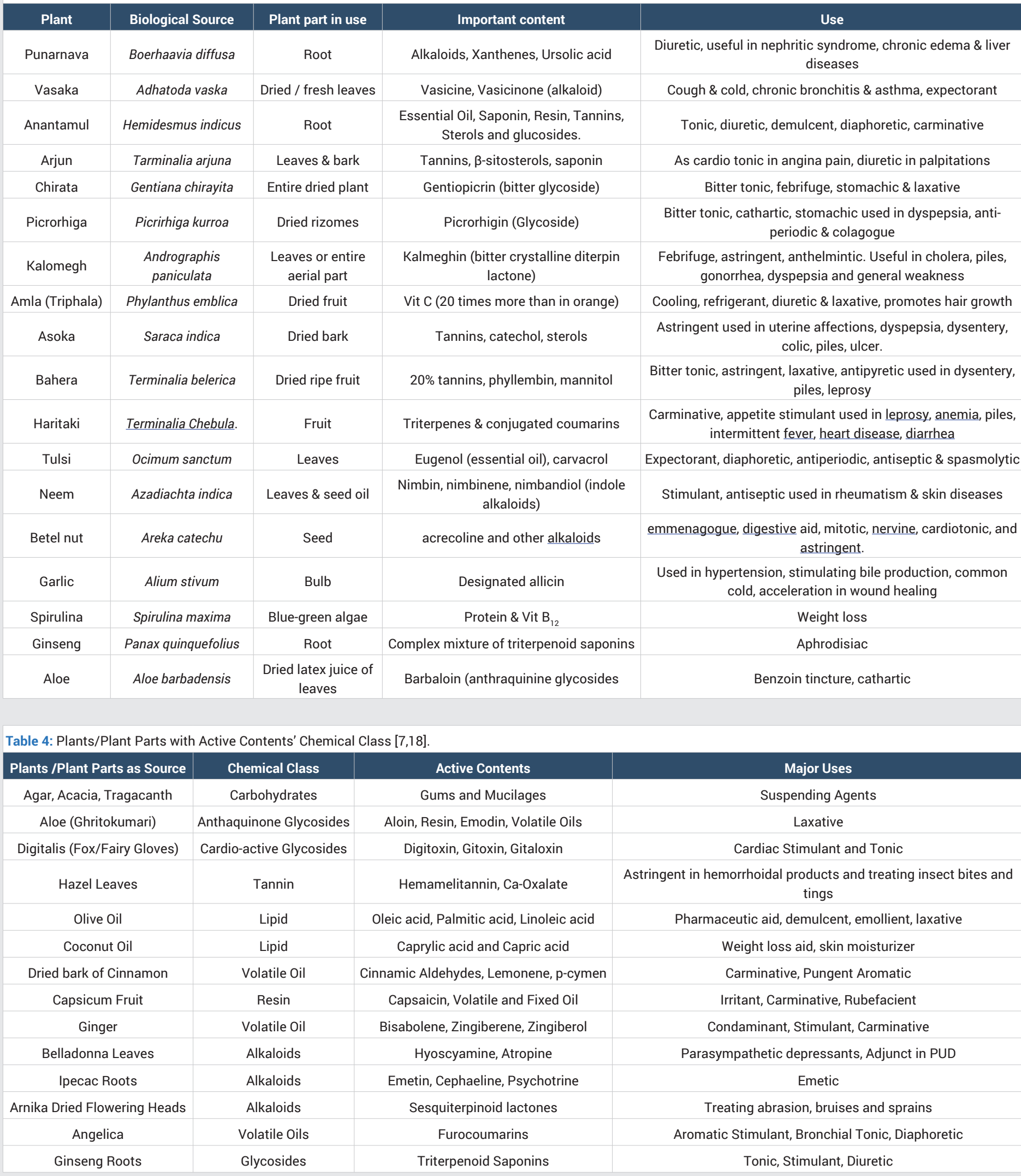

of the kavirajes also use snakes' blood, birds or other animal parts, fish or fish oil and others chemicals as ingredients of their medicines. Dilution, dose, administration time and mixture played a significant role in need of combinations of useful extracts by the traditional practitioners [25].

\section{Prospect of traditional medicines in bangladesh}

At present, there are 295 Unani, 201 Ayurvedic, 15 Herbal, 79 Homeopathic companies operating in Bangladesh compared to 300 (approx.) Allopathic companies (Website DGDA). Herbal 
Table 5: Popular Home Remedies with Traditional Medicines [20].

\begin{tabular}{c|c|c|c|c}
\hline Plant Local Name & Scientific Name & Commonly Used Plant Part & Remedial Option (s) \\
\hline Mango & Mangifera indica & Bark & Mango Juice with ginger for aid in Jaundice \\
\hline Turmaric (Holud) & Curcuma longa & Rhizome & Gastric Disorder \\
\hline Bael & Aegle marmelos & Fruit & Ceucorrhea and Stomachache \\
\hline Arjun & Terminalia arjuna & Bark & Helminthiasis, should be taken in empty stomach \\
\hline Pineapple & Ananas comosus & Fruit & Along with ginger for Jaundice \\
\hline Helencha & Enhydra fluctuans & Leaves & Gum Infection \\
\hline Thankuni & Centella asiatica & Leaves & Root Juice for Helminthiasis \\
\hline Supari & Areca catechu & Root & Cold with coughs \\
\hline Boitha shak & Chenopodium album & Leaves & Cough and Cold \\
\hline Bashok & Adhatoda vasaka & Leaves & Gingivitis, Stomach upset \\
\hline Telakuchi & Coccinia grandis & Roots/leaves & Brain tonic \\
\hline Neem & Antelaea azadirachta & Leaves and bark & Cough and cold \\
\hline Shankhapushpi & Convolvulus pluricaulis & Whole aerial part & Roots for arthritic joint pain and leaves for lowering blood sugar level \\
\hline Ginger & Zingiber officinale & Rhizome & Emetic, diaphoretic and expectorant \\
\hline Anantamul & Tylophora indica & Leaves & Bitter tonic, febrifuge, laxative \\
\hline Chirata & Swertia chirata & Bitter stick & Promote hair Growth \\
\hline Asoka & Saraca indica & Dried bark & Expectorant, diaphoretic. Antiperiodic \\
\hline Amla & Embelic myrobalan & Dried fruit & Managing Constipation \\
\hline Tulsi & Ocimum sanctum & Leaves & Uterine affections, biliary colic, pimples and menorrhagia \\
\hline Ispaghula & Plantago ovata & Seeds & \\
\hline & & &
\end{tabular}

Table 6: Popular Cosmetic Uses of Traditional Medicines [21,22].

\begin{tabular}{|c|c|c|}
\hline Plant/Plant Part & Scientific Name & Active Component \\
\hline Coconut oil & Cocos nucifera & Glycerides of lower chain fatty acids \\
\hline Sunflower oil & Helianthus annuus & lecithin, tocopherols, carotenoids and waxes. \\
\hline Aloe vera (Ghrtokumari) & Aloe indica & leucine, isoleucine, saponin glycosides, vitamins \\
\hline Jojoba oil & Simmondsia chinenesis & Palmitic acid, stearic acid, oleic acid \\
\hline Carrot & Daucus carota & $\beta$-carotene \\
\hline Gingko & Ginkgo biloba & flavone glycoside quercetin and kaempferol \\
\hline Green tea & Camellia sinensis & $\begin{array}{c}\text { (2)-epicatechin (EC), } \\
\text { EGC, (2)-EC-3-gallate, EGCG }\end{array}$ \\
\hline Calendula & Calendula officinalis & $\begin{array}{c}\text { a-thujene, a-pinene, 1,8-Cineole, dihydrotagetone anc } \\
\text { T-muurolol }\end{array}$ \\
\hline Turmeric & Curcuma longa & $\begin{array}{l}\text { zingiberene, curcumol, curcumenol, eugenol, } \\
\text { tetrahydrocurcumin }\end{array}$ \\
\hline Henna Leaves (Mehendi) & Lawsonia inermis & Lawsone, gallic acid, glucose, mannitol, fats, resin \\
\hline Rose oil & Rosa damascena & citronellol, phenyl ethanol, geraniol, nerol, farnesol \\
\hline Ginseng & Panax ginseng & Triterpenoid Saponins \\
\hline Onion & Allium cepa & $\begin{array}{c}\text { flavonoids (quercetin and } \\
\text { kampferol) }\end{array}$ \\
\hline Rosemary & Rosmarinus officinalis & caffeic acid and rosmarinic acid \\
\hline Cucumber & Cucumis sativa & vitamin $\mathrm{C}$, vitamin $\mathrm{K}$, and potassium \\
\hline Eucalyptus oil & Eucalyptus cinerea & $\begin{array}{l}\text { Eucalyptol, limonene, a-pinene, a- phellandrene, } \\
\text { } \beta \text {-pinene }\end{array}$ \\
\hline Pumpkin & Cucurbita pepo & linoleic, oleic, palmitic and stearic acid \\
\hline
\end{tabular}

\section{Intended Use}

Skincare, Promotes Hair growth

\section{Skincare}

Skincare, hair growth

Replenishes skin and hair lose

$$
\text { Anti-ageing }
$$

Anti-ageing

Skin protection and Anti-ageing

Anti-oxidant, skin repair

UVB induced sunburn

Staining hair, nails and beard

clearing, cleansing, and purifying effect on the female sex organs skin's metabolism, reduce keratinization, alleviate wrinkling and enhance skin whiteness

externally as a poultice for acne, boils, abscesses and blackheads, speed healing.

$$
\text { to stimulate }
$$

growth of hair as a rinse

$$
\text { soothing to }
$$

irritated skin and treatment of hyperpigmentation

Tingling Hair Conditioner, promoted hair growth

$$
\text { syphilitic }
$$

sores, herpes lesions, pimples and blackheads medicines are increasingly popular in local and global markets. More than 20 firms seek licenses to come into the sector. Herbal medicines are set to witness an investment boost as over 20 companies have lined up for licenses from the drug administration to manufacture such medicines to exploit business potentials in the sector, still almost untapped [26]. DGDA has received nearly two dozen of applications seeking approval to make herbal medicine. The latest approval was 
given to Radiant Nutraceuticals Ltd, which is set to join the fray with three existing operators -- Square, ACME and Modern -with Square Herbal and Nutraceuticals being the pioneer in the segment. Industry insiders said allopathic pharma market in Bangladesh is worth around Tk 4,000 crore, while the market size for herbal medicines including Ayurvedic and Unani stands at more than Tk 1,000 crore. The sector started pulling attention after the government had endorsed herbal medicine in the drug policy along with two other traditional branches of medicine - - Ayurvedic and Unani. Later the sector received a further boost as the government termed herbs and herbal medicine as one of the five priority sectors to diversify the country's export

Table 7: Common Traditional Plants as Anti-venoms [23,24].

\begin{tabular}{|c|c|c|}
\hline Plant Name & Plant Part in Use & General Practice \\
\hline Allium sativum & Leaves & First aid for snake bite \\
\hline $\begin{array}{l}\text { Achyranthes } \\
\text { aspera }\end{array}$ & $\begin{array}{l}\text { Roots, Leaves } \\
\text { and Stem }\end{array}$ & Snake bite \\
\hline $\begin{array}{l}\text { Abelmoschus } \\
\text { moschatus }\end{array}$ & Roots & Snake bite \\
\hline $\begin{array}{l}\text { Averrhoa } \\
\text { Carambola }\end{array}$ & Fruits & Datura poisoning \\
\hline $\begin{array}{l}\text { Capsicum } \\
\text { frutescens }\end{array}$ & Leaves & Applied locally in bee sting \\
\hline Citrus limon & Stem and Fruit & Snake bite \\
\hline Curcuma longa & Rhizome & Applied in leech bites to heal the wound \\
\hline Datura metel & Fruit & Given once daily to patient for dog bite \\
\hline Oryza sativa & Grain & Rubbed on the body in caterpillar allergy \\
\hline $\begin{array}{l}\text { Nicotiana } \\
\text { tabacum }\end{array}$ & Leaves & Crushed leaves for removing leeches \\
\hline $\begin{array}{l}\text { Xanthium } \\
\text { strumarium }\end{array}$ & Leaves & Food poisoning \\
\hline $\begin{array}{l}\text { Saccharum } \\
\text { bengalense }\end{array}$ & Root & $\begin{array}{l}\text { Taken orally or applied locally thrice daily till } \\
\text { recovery in snake bite. }\end{array}$ \\
\hline
\end{tabular}

Table 8: Severe Adverse Effects Reported with Commonly Used Herbs.

\begin{tabular}{|c|c|c|}
\hline Local Name & Scientific Name & Poisonous effects \\
\hline Kuchila & $\begin{array}{l}\text { Strychnos nux- } \\
\quad \text { vomica }\end{array}$ & Respiratory failure, nausea, muscle twitching [31 \\
\hline Antamul & Tylophora indica & $\begin{array}{l}\text { Plant juice causes vomiting, } \\
\text { unconsciousness, and death [31] }\end{array}$ \\
\hline Aloe Vera & Aloe indica & Nephrotoxicity and group 2B carcinogenic [32] \\
\hline $\begin{array}{l}\text { Eucalyptus } \\
\text { oil }\end{array}$ & $\begin{array}{l}\text { Eucalyptus } \\
\text { globulus }\end{array}$ & Irritation of skin and nostril of children [33] \\
\hline Betel Nut & Areca catechu & Nausea, vomiting, dizziness, chest discomfort [34 \\
\hline Coconut oil & Cocos nucifera & Oxidative stress, hyperlipidemia [35] \\
\hline Ginseng & Panax ginseng & $\begin{array}{l}\text { cardiovascular and renal toxicity, hepatotoxicity, } \\
\text { reproductive toxicity [36] }\end{array}$ \\
\hline Henna & Lawsonia inermis & $\begin{array}{l}\text { Hemolytic crisis in individuals deficient in glucose } \\
\text { 6-phosphate dehydrogenase (G6PD) [37] }\end{array}$ \\
\hline Green Tea & Camellia sinensis & $\begin{array}{c}\text { restlessness, confusion, psychomotor agitation, } \\
\text { EGCG (component of green tea) has anti-folate } \\
\text { activity [38] }\end{array}$ \\
\hline Cucumber & Cucumis sativus & Hair loss [39] \\
\hline Rosemary & $\begin{array}{l}\text { Rosmarinus } \\
\text { officinalis }\end{array}$ & Not safe in pregnancy [40] \\
\hline Turmeric & Curcuma longa & Not safe in pregnancy [41] \\
\hline
\end{tabular}

Table 9: Drug Interaction Reported with Common HDS [42]
HDS

Interaction Possibility

Acacia

Amoxicillin

Aloe Vera

Digoxin

American Warfarin, Enalapril, Nitroglycerin,

ginseng Spironolactone

Aspirin, cilostazol, clopidogrel,

Ginkgo dipyridamole, heparin, ibuprofen, naproxen, ticlopidine, warfarin

\begin{tabular}{c|c|c} 
Green tea & Ephedrine & Risk of stimulatory adverse effects \\
$\begin{array}{c}\text { Evening } \\
\text { primrose }\end{array}$ & Warfarin & Risk of bleeding \\
\hline
\end{tabular}

Garlic Ritonavir, Saquinavir, Warfarin

Potential Impact
Reduce absorption due to presence of oleoresin.

Increased Digoxin Toxicity

Lowers effects of warfarin and increased others hypotensive effects due to glycoside contents similar to digoxin

Increases risk of bleeding

Reduce antiviral effects and risk of bleeding basket. Industry people observed that Bangladesh has prospect in making footsteps on the global market for medicinal plant and products as nearly 650 medicinal plant species have been identified to be in use in Bangladesh with around 25 plants having high value. A new claim is herbal medicine differs from Ayurvedic and Unani medicines due to its unique manufacturing process, although all the three branches of medicine depend mainly on medicinal plants. The herbal medicine market, which has been expanding gradually since 1980, will exceed Tk 2,500 crore by 2020 , herbalists predicted. The sales volume of herbal medicines jumped to Tk 1,000 crore in 2010 against Tk 1 crore in 1980. The nation's 210 Ayurvedic establishments produce 272 types of medicines [27].

\section{Misuse and abuses of traditional medicine}

Traditional medicine has its own limitations. It takes time to cure the patient and restore health. Or there should be enough study using these drugs in specific indication or any sorts of well being like anti-ageing or antioxidant properties. Different tea combinations of Tulsi, Ginger, pepper and neem suggested by fitness trainers as slimming aids and people are spending a lot as well [28]. Another worsening feature is heavy metal toxicity by the marketed products having poor prior quality control. Herb extracts are best while taken fresh, dried and long-term preservation gives rise poisoning from the preservatives in use [29]. Some concerned people noticed that ginseng preparations are endowed with Sildenafil (VIAGRA) and claiming sexual enhancement, whereas ginseng is best known for anti-ageing activities. Substance use among women and children is increasingly becoming the focus of attention and merits further research. Abrupt use of herbal cosmetics and frequent use of herbal cough syrups thinking that natural means safe also reported. After caffeine, alcohol, and nicotine, betel nut (PAAN) is the fourth most abused substance in the world, chewed alone or in a mixture of other spices for its stimulant effect [30]. And Aloe Vera is blindly taken by so called health conscious people. The poisonous effects of these abuses and misuses will be discussed later part of this article.

Poisonous and serious side effects found with traditional plant medicines

WAPIC reported undiluted essential oils on sensitive skin or 
in the nostrils can irritate or burn in children. Certain marketed products reported kidney or liver damage (Table 9), and are sometimes adulterated with steroids, pesticides, antibiotics or harmful metals. Chronic use of betel nut can cause addiction, as well as red staining of the teeth and gums and the potential for oral cancers. Mushroom poisoning is said to be most severe though no fatal incidents have been reported despite the lack of modern medical facilities.

Again, herbal medicines contain a combination of pharmacologically active plant constituents that are claimed to work synergistically to produce an effect greater than the sum of the effects of the single constituents. Even it is a single drug, it is pharmacologically active, might interact with other drugs by compete any receptor or enzymatic system.

\section{Safety issues and recommendations}

Lack of side effects do not mean taking a medicine without any expert's recommendations. One should always take medicine consulting an expert of allied field. Moreover, opt for well-known trusted sources when it comes to buying medicines. With traditional medicine, there is always risk of counterfeits. And while their effectiveness varies from person to person, such traditional medicinal systems are often the last resort for people, especially when the western ones fail them. Definitely we get energized with a number of active herbal ingredients posing on the package but a little but relevant question rise how all these ingredients are altogether found at a time as plant constituents varies in different seasons. Moreover, some plants should not be found anytime and every time. And if we are convinced with the fact that they collected and stored for selling year-round, where's the guaranty that they were stored in a prescribed manner, in Bangladesh where BSTI seal creates doubts sometimes. A mushrooming of folk healer's shops clearly visible with their unusual claim of complete recovery from ulcer, cancer, asthma, erectile dysfunctions, alopecia, AIDS and by born complications. A common scenario of roadside hawkers surrounded by a lot of many unprivileged people claiming leeches' oils for stronger penile erection, whereas leeches do not possess oil at all. Plants have provided us with some of our most effective drugs, including aspirin, made from willow bark. Moreover, at least 7,000 medical compounds in the modern pharmacopoeia are derived from plants. Nearly two thirds of traditional medicinal plants are as effective as medical drugs but it is still difficult to get a sound advice. A growing number of people are looking for guidance on the Internet while others believe dishonest ads. It is strictly recommended that plant drugs are miraculous, better avoid plant drugs as food supplements, they can't be always safe as they are natural and taking expert's advice before use.

\section{Conclusion}

Safety is when any drug is ingested following an expert. Indiscriminate use of plant medicine may rise to severe longterm poisoning and short-term adverse events. Traditional plants have vast opportunities to explore, conducting extensive research necessary for their rational use in Bangladesh and abroad. Companies with big reserve can invest further to bring qualified researchers from abroad to see their further scope of extension for both business purpose and mankind. These dynamic fields are at the intersection of phytochemistry and plant biology and are concerned with the evolution mechanisms and systematics of medicinal plant genomes, origin and evolution of the plant genotype and metabolic phenotype, interaction between medicinal plant genomes and their environment, the correlation between genomic diversity and metabolite diversity, and so on. Use of the emerging high-end genomic technologies can be expanded from crop plants to traditional medicinal plants, in order to expedite medicinal plant breeding and transform them into living factories of medicinal compounds. The utility of molecular phylogeny and phylogenomics in predicting chemodiversity and bioprospecting is also highlighted within the context of natural-product-based drug discovery and development.

\section{Acknowledgement}

It's a great gratitude and honor to be a part of healthcare research and education. I am thankful to Dr. Choudhury Mahmood Hasan to give his precious time to review my article, providing books, journals and newsletters. I am also grateful to seminar library of Faculty of Pharmacy, University of Dhaka for the books, journals and thesis reports in the allied field. The greatest help was from my students who paid interest in my topic as class lecture and encouraged to write such article comprising traditional medicines, their prospect and limitations. Despite a great scarcity of funding this purpose from any authority, the experience was good enough to carry on research.

\section{References}

1. Warrier M (2009) Seekership, Spirituality and Self-Discovery Ayurveda Trainees in Britain. Asian Med (Leiden) 4: 423-451. Link: https://tinyurl.com/yal3luzq

2. Markbunn (2015) Ayurveda \& Vedic Science: Web The Science of Life

3. Proma AM (2018) The magic of Ayurvedic medicines. The Daily Star.

4. Agrawal DP, Tiwari L. Ayurveda: the Traditional Indian Medicine System and its Global Dissemination. Link: https://tinyurl.com/y8fjaq6d

5. Botanicals WB. Vata, Pitta, Kapha (2018) An Introduction to Three Energetic Forces of Nature. Learning Ayurveda Updated. Link: https://tinyurl.com/ybnw4uys

6. Web Copper H2O. Ayurvedic Medicine Origin, History and Principles. Link: https://tinyurl.com/yc6yv7au

7. Textbook of Pharmacognosy (Second Edition) by Mohammad Ali, Publisher (2012) CBS Publishers \& Distributors Pvt. Ltd. Publication. Link: https://tinyurl.com/ybr4ldd8

8. Masic I, Skrbo A, Naser N (2017) Contribution of Arabic Medicine and Pharmacy to the Development of Health Care Protection in Bosnia and Herzegovina - the First Part. Med Arch 71: 364-372. Link: https://tinyurl.com/yb69opwm

9. Web Whole Health Now. The Founder of Homeopathy. Link: https://tinyurl.com/an2ohw

10. Britannica WE. Siddha medicine. Link: https://tinyurl.com/yasf374u 
11. Tyler VE, Brady L, James E, Pharmacognosy R (1981) 8th edition. Published by Lea \& Febiger, Philadelphia, PA 19106. Link: https://tinyurl.com/y97llen2

12. ANM Alamgir (2017) Therapeutic Use of Medicinal Plants and Their Extracts: Volume 1 Pharmacognosy. Publisher: Springer International Publishing. Link: https://tinyurl.com/ybb9lhyr

13. Ashraf MA, Khatun A, Sharmin T, Mobin F, Tanu AR, et al. (2014) MPDB 1.0: a medicinal plant database of Bangladesh. Bioinformation 10: 384-386. Link: https://tinyurl.com/y74mhhka

14. Rakotoarivelo $\mathrm{NH}$, Rakotoarivony $\mathrm{F}$, Ramarosandratana $\mathrm{AV}$, Jeannoda $\mathrm{VH}$ Kuhlman AR, et al. (2015) Medicinal plants used to treat the most frequent diseases encountered in Ambalabe rural community, Eastern Madagascar. J Ethnobiol Ethnomed. 15; 11:68. Link: https://tinyurl.com/yantzktx

15. Yuan H, Ma Q, Ye L, Piao G (2016) The Traditional Medicine and Modern Medicine from Natural Products. Molecules 21: E559. Link: https://tinyurl.com/y9mxblgz

16. WHO guidelines on good manufacturing practices (GMP) for herbal medicines 2017. Link: https://tinyurl.com/y7wpjrwj

17. Tripathi IP (2010) Chemistry, Biochemistry and Ayurveda of Indian Medicinal Plants. Publisher: International E Publication.

18. Web USA Forest Service. Active Plant Ingredients Used for Medicinal Purposes. Link: https://tinyurl.com/y7stdxe6

19. Sheikh H (2018) Alternative medicine in Bangladesh. Stethoscope. The Independent.

20. WHO Traditional Herbal Remedies for Primary Health Care. Link: https://tinyurl.com/y9zl94oc

21. Joshi LS, Pawar HA. Herbal Cosmetics and Cosmeceuticals: An Overview Nat Prod Chem Res 3: 170. Link: https://tinyurl.com/y9wve9gz

22. Aburjai T, Natsheh FM (2003) Plants used in cosmetics. Phytother Res 9871000. Link: https://doi.org/10.1002/ptr.1363

23. Teron R, Borthakur SK (2013) Folklore claims of some medicinal plants as antidote against poisons among the Karbis of Assam, India. Pleione 7: 346356. Link: https://tinyurl.com/y8q62j9r

24. Jahan R, Jannat K, Maidul Islam MM, Shova NA, Shah R, et al. (2018) A Review of Two Plants Used Traditionally in Bangladesh for Treatment of Snake Bites. J Pharmacol Clin Toxicol 6: 1113. Link: https://tinyurl.com/yacrvvuk

25. Rashid S. Chapter 5, Heritage, Folk Medicine and Kaviraji Treatment in Bangladesh Traditional Medicine Sharing Experiences from the Field Eivind Falk. Link: https://tinyurl.com/y8xk4n64

26. Parvez S (2009) Herbal medicines get new lease of life. The Daily Star. Link: https://tinyurl.com/y957hs9m
27. Dhaka U (2012) Herbal medicine market to cross Tk 2,500cr by 2020 . The Daily Star. Link: https://tinyurl.com/ycb2cyj8

28. Ekor M (2014) The growing use of herbal medicines: issues relating to adverse reactions and challenges in monitoring safety. Front Pharmacol 4 177. Link: https://tinyurl.com/yay2c59q

29. Tchounwou PB, Yedjou CG, Patlolla AK, Sutton DJ (2012) Heavy metal toxicity and the environment. Exp Suppl 101: 133-164. Link: https://tinyurl.com/hjv9fvp

30. Bhat SJ, Blank MD, Balster RL, Nichter M, Nichter M (2010) Areca nut dependence among chewers in a South Indian community who do not also use tobacco. Addiction 105: 1303-1310. Link: https://tinyurl.com/ybehz3nb

31. Basher A, Islam QT (2014) Plants and Herbal Poisoning in Bangladesh Clinical Toxinology 1-19. Link: https://tinyurl.com/y84xsubg

32. Guo X, Mei N (2016) Aloe vera: A review of toxicity and adverse clinical effects J Environ Sci Health C Environ Carcinog Ecotoxicol Rev 34: 77-96. Link: https://bit.ly/2MuNVkq

33. Kumar KJ, Sonnathi S, Anitha C, Santhoshkumar M (2015) Eucalyptus oil poisoning. Toxicol Int 22: 170-171. Link: https://goo.gl/xVewga

34. Jou-Fang D, Ger J, Wei-Jen T, Wei-Fong K, Chen-Chang Y (2001) Acute Toxicities of Betel Nut: Rare but Probably Overlooked Events Clinical Toxicology 39: 355-360. Link: https://goo.gl/pQNFvY

35. Boemeke L, Marcadenti A, Busnello FM, Bertaso C, Gottschall A (2015) Effects of Coconut Oil on Human Health Open Journal of Endocrine and Metabolic Diseases 84-87. Link: https://goo.gl/qKn6mG

36. Paik DJ, Lee CH (2014) Review of cases of patient risk associated with ginseng abuse and misuse. J Ginseng Res 39: 89-93. Link: https://goo.gl/Bbn8Rq

37. Hazra A (2002) Adverse reactions to henna Indian Journal of Pharmacology 34: 436-437. Link: https://goo.gl/K4tyCB

38. Nawab A, Farooq N (2015) Review on green tea constituents and its negative effects The Pharma Innovation Journal 4: 21-24. Link: https://goo.gl/swCg3A

39. Assouly P (2018) Hair Loss Associated With Cucurbit Poisoning JAMA Dermatol 154: 617-618. Link: https://goo.gl/U8RtQD

40. WebMD. Vitamins and Supplements (rosemary). Link: https://goo.gl/nAsFeA

41. WebMD. Vitamins and Supplements (turmeric). Link: https://goo.gl/83aFzj

42. Tsai HH, Lin HW, Simon PA, Tsai HY, Mahady GB (2012) Evaluation of documented drug interactions and contraindications associated with herbs and dietary supplements: a systematic literature review Ernst. Int J Clin Pract 66: 1019-1020. Link: https://goo.gl/nFfbWg

Copyright: (c) 2019 Mohiuddin AK. This is an open-access article distributed under the terms of the Creative Commons Attribution License, which permits unrestricted use, distribution, and reproduction in any medium, provided the original author and source are credited. 